\title{
ARTICLE \\ Influence of combined treatment with naltrexone and memantine on alcohol drinking behaviors: a phase II randomized crossover trial
}

Suchitra Krishnan-Sarin ${ }^{1}$, Stephanie S. O’Malley ${ }^{1}$, Nicholas Franco ${ }^{1}$, Dana A. Cavallo ${ }^{1}$, Jeanette M. Tetrault ${ }^{1}$, Julia Shi ${ }^{1}$, Ralitza Gueorguieva ${ }^{1}$, Brian Pittman ${ }^{1}$ and John H. Krystal ${ }^{1}$

Glutamate and opioid systems play important roles in alcohol drinking behaviors. We examined if combined treatment with the NMDA antagonist memantine and the opioid antagonist naltrexone, when compared with naltrexone alone, would have a greater influence on alcohol drinking behaviors. Fifty-six, non-treatment-seeking heavy drinkers, with alcohol dependence and a positive family history (FHP) of alcoholism, participated in a randomized, double-blind, crossover trial, including two 6-8 days treatment periods, separated by a 6-day washout, and 3 alcohol drinking paradigm (ADP) sessions. After the first baseline (BAS) ADP1 session, participants were randomized to receive either naltrexone (NTX; $50 \mathrm{mg} /$ day) + placebo memantine, or NTX (50 mg/day) + memantine (MEM; $20 \mathrm{mg} /$ day), during the first treatment period, following which they completed ADP2. After a 6-day washout, participants were crossed over to the treatment they did not receive during the first treatment period, following which they completed ADP3. During each ADP, participants received a priming drink of alcohol followed by 3 1-hour, self-administration periods during which they had ad-lib access to 12 drinks. Individually, both NTX and NTX + MEM, when compared to BAS ADP1, significantly reduced the number of drinks consumed $\left(p^{\prime} s<0.001\right)$ and craving $\left(p^{\prime} s<0.001\right)$. When comparing NTX + MEM vs. NTX on number of drinks consumed, there was a significant treatment* sequence interaction $(p=0.004)$. Specifically, when NTX + MEM followed NTX alone, NTX + MEM resulted in a further reduction in drinking (mean: $-1.94 ; 95 \% \mathrm{Cl}:-2.6,-0.8, p=0.0005)$. However, when NTX alone followed NTX + MEM, NTX alone did not lead to further reduction in drinking (mean: 0.59; $95 \%$ Cl: $-0.67,1.43$, $p=0.47$ ). Similar patterns were observed for alcohol craving; specifically, a significant reduction in craving was observed when NTX + MEM followed NTX alone $(p=0.009)$, but craving reduction was maintained when NTX + MEM was followed by NTX alone. Neither treatment condition significantly influenced alcohol-induced stimulation or sedation. Memantine (at a dose of 20 mg/day) enhances the efficacy of naltrexone ( $50 \mathrm{mg} /$ day) in reducing alcohol drinking and craving among FHP drinkers with beneficial effects that appear to carryover after discontinuation of memantine treatment.

Neuropsychopharmacology (2020) 45:319-326; https://doi.org/10.1038/s41386-019-0536-z

\section{INTRODUCTION}

The NMDA glutamate-receptor (NMDA-R) is among the highest affinity targets for ethanol in the brain [1] and its function is modulated by doses of ethanol that produce intoxication [2, 3]. The NMDA-R receptor antagonist ketamine is known to have alcohol-like intoxicating effects, and both the presence of an alcohol use disorder (AUD) [4] and a positive family history of alcoholism (FHP) [5, 6] are associated with reductions in ketamine's sedative and cognition-impairing effects. Thus, NMDA-R antagonism by alcohol may be a key regulator of the ability to judge intoxication levels and regulate consumption $[4,7]$. Further, chronic alcohol drinking results in a hyperglutamatergic state with upregulation of NMDA-Rs and associated signaling [4, 8-10], an effect which may be related to the severity of alcohol use disorder (AUD) [11]. Thus, medications that target the NMDA-R changes produced by chronic alcohol use and restore balance in glutamate activity may hold promise for the treatment of alcohol drinking behaviors.
One such agent is memantine, the uncompetitive NMDA-R antagonist. Memantine was found to reduce alcohol drinking in animals [12], decrease cue-induced alcohol craving and alcohol withdrawal in drinkers [13-16], reduce alcohol use when combined with valproic acid in patients with bipolar disorder and alcohol dependence [17], and normalize brain reward circuit activation in response to monetary rewards and alcohol cues in FHP social drinkers [18]. Our earlier findings suggested that memantine's effects on alcohol use behaviors are dose dependent; specifically, while a dose of $20 \mathrm{mg} /$ day reduced alcohol craving in heavy drinkers [19] it did not reduce drinking, and a higher dose of $40 \mathrm{mg} /$ day did not reduce alcohol craving and led to increases in alcohol drinking and alcohol-induced stimulation among heavy drinkers who were more impulsive. Thus, while memantine appears to reduce alcohol craving, its potential efficacy as a monotherapy for AUDs may be offset by its tendency to disinhibit drinking in those who are impulsive, especially at higher doses. Therefore, more nuanced approaches of altering NMDA-R function may be needed for reducing drinking.

${ }^{1}$ Department of Psychiatry, Yale University School of Medicine, Connecticut Mental Health Center, Office S-208, 34 Park Street, New Haven, CT 06519, USA Correspondence: Suchitra Krishnan-Sarin (suchitra.krishnan-sarin@yale.edu)

Received: 3 May 2019 Revised: 20 September 2019 Accepted: 25 September 2019

Published online: 7 October 2019 
The goal of this study was to examine one such approach involving targeting the NMDA-R in combination with opioid receptors which are also known to play a significant role in alcohol drinking behaviors. In fact, the effects of alcohol on the corticolimbic reward circuitry are modulated through both the opioid receptors and NMDA-R signaling $[20,21]$, and therefore combined targeting of both systems could lead to optimal suppression in ventral striatal dopaminergic activity (responsible for reward-induced drinking) and greater reductions in drinking and craving. Support for this approach also derives from evidence of significant cross-talk between mu-opioid-receptor-associated Gprotein signaling and glutamatergic neurotransmission in the cortico-striatal reward circuitry [22], and colocalization of NMDARs and mu-opioid-Rs in multiple brain areas including the nucleus accumbens [23] and nucleus tractus solitarius [24]. NMDA antagonists prevent the development of opioid tolerance, dependence and withdrawal [25-29]. Further, opioid antagonists potentiate the anxiogenic and anhedonic effects of a low subantidepressant dose of ketamine [30] and reduce glutamatergic response to alcohol administration in the nucleus accumbens [31].

We hypothesized that combined targeting of the glutamate system, with a dose of memantine that reduces alcohol craving but does not disinhibit drinking [20 mg/day; [19]], and the opioid system, with a moderate dose of naltrexone $(50 \mathrm{mg} /$ day) that reduces alcohol drinking and is used to treat AUDs [32,33], would lead to greater reductions in alcohol drinking and craving than naltrexone alone. We conducted this proof-of-concept study using an alcohol drinking paradigm (ADP); similar paradigms have been used to evaluate the effects of medications on drinking behaviors $[32,34-39]$. Since the presence of FHP is associated with both enhanced NMDA-R function and AUD's [4], we conducted this trial in FHP drinkers. We also explored the impact of impulsivity on drinking and craving outcomes.

\section{METHODS}

\section{Design overview}

This trial used a randomized, double-blind, two sequence crossover design with a 1:1 allocation ratio (Supplement Fig. 1), was approved by the Yale Human Investigations Committee, registered in clinicaltrials.gov (NCT01519063), followed the National Advisory Council for Alcohol Abuse and Alcoholism guidelines [40], and was completed between January 2012 and April 2017.

All ADP sessions were held at the Hospital Research Unit (HRU) of Yale/New Haven Hospital (YNHH). Eligible participants first completed a baseline ADP1 to acclimatize them to the procedures and ensure that they would drink; those who did not drink during the ad-lib periods in ADP1 were discontinued. Participants who continued were randomized to one of two treatment sequences1) NTX alone ( $50 \mathrm{mg} /$ day NTX with placebo MEM) followed by NTX + MEM (50 mg/day NTX with $20 \mathrm{mg} /$ day MEM) or 2) NTX + MEM followed by NTX alone. Each treatment sequence consisted of two 6-8-day outpatient treatment periods (to allow for exposure to 4-5 half-lives of the drug), separated by a 6-day washout. Participants completed ADP2 and ADP3 at the end of each treatment period. After ADP3, all participants completed a 1-week follow-up visit during which they received a motivational intervention (from a clinical psychologist) to motivate them to seek treatment for their drinking, and adverse events and drinking were assessed at this and a one-month follow up visit (data not presented).

\section{Participants}

Heavy drinkers who were not treatment seeking and consumed 25-70 drinks/week for men and 20-65 drinks for women [Timeline Follow-Back method; TFLB; [41]], were recruited from the community. Following written informed consent, a psychological evaluation, physical examination, and laboratory assessments including urine toxicology and liver function tests were completed and reviewed by the study physician. Eligible participants were FHP [parent and one other first degree relative with alcohol problems; Family History Assessment Module [42]] drinkers who met DSM-IV criteria for alcohol dependence (SCID-IV; First et al. [43]). Participants were excluded if they (1) had contraindications to memantine, naltrexone or alcohol, (2) had alcohol withdrawal at any appointment [revised Clinical Institute Withdrawal Assessment for Alcohol (CIWA-Ar) > 8; [44], (3) were abusing or dependent on substances other than alcohol or nicotine, (4) had other current Axis-1 diagnoses, (5) were not stable on prescribed antidepressants/anxiolytics, or (5) were pregnant or nursing. Participants had to have a negative breath alcohol (BAC) test prior to obtaining informed consent, and a BAC below 0.02 and a negative CIWA-Ar prior to the start of the ADP session.

\section{Medication treatment}

The study statistician generated the randomization schedule using block randomization with random block sizes of 2 and 4, and the YNHH Investigational pharmacy randomized participants and provided naltrexone tablets and memantine and placebo memantine in identical capsules. All other personnel were blind to treatment assignment.

Participants started with $25 \mathrm{mg} /$ day of NTX on Day 1 and then received $50 \mathrm{mg} /$ day of NTX from Day 2 onwards. MEM (or placebo MEM) was initiated on Day 2 and titrated-up as follows: $5 \mathrm{mg}$ on Day 2, $10 \mathrm{mg}$ on the Day 3 and $20 \mathrm{mg} /$ day from Days 4 onwards. Participants arrived at the clinic between 10 am and $12 \mathrm{pm}$ daily to take their study medications and complete craving, drinking, and adverse event assessments. On days 6-8 of each treatment period (depending on HRU availability), participants were admitted to the HRU at $10 \mathrm{am}$ and received their last dose of medication.

Alcohol drinking paradigm (ADP)

ADP sessions ran from 2-7 pm. After completing baseline assessments, all participants had to consume a priming dose (PD) of alcohol at $3 \mathrm{pm}$ and alcohol effects were monitored for $1 \mathrm{~h}$. This was followed by three 1 -h ad-lib self-administration periods (4-5 pm, 5-6 pm, 6-7 pm); during each ad-lib period participants were presented with a tray of four drinks and invited to choose between consuming each of the drinks or receiving $\$ 3$ per drink (total of 12 drinks over $3 \mathrm{~h}$ ). Following completion of the ADP at 7 pm, participants spent the night at the HRU and were discharged the next morning.

Alcohol dose. The YNHH Investigational Pharmacy calculated and delivered doses of each participants preferred alcohol to the HRU; the doses were designed to raise blood alcohol levels (to $0.03 \mathrm{~g} / \mathrm{dl}$ for priming drink and $0.015 \mathrm{~g} / \mathrm{dl}$ for all other drinks) based on a formula that considers the gender, weight, and age of the participant [45]. Each alcohol dose was mixed with the participant's preferred non-caffeinated, non-carbonated mixer in a 1:3 ratio. Each participant's preferred alcohol (80 proof spirits) and mixer were determined at an intake appointment and kept constant at each ADP.

\section{Assessments}

\section{Primary outcomes}

Drinks consumed: Total number of drinks consumed during the three ad-lib periods.

Alcohol craving: Craving measured $30 \mathrm{~min}$ prior to the priming dose (baseline), and then 10, 20,30, 40, and 50 min during the PD period and every half hour during each ad-lib period (i.e., 90, $120,150,180,220$, and $240 \mathrm{~min}$ ) using the Alcohol Urge questionnaire [46]. 


\section{Secondary outcomes}

Alcohol-Induced Stimulation/Sedation were determined at 10, 20 , and 50 min during the PD period, and at the end of each of the three ad-lib periods, with the Biphasic Alcohol Effects Scale [BAES; [47]], a 14-item scale that measures the stimulant and sedative effects of alcohol. We used the brief BAES, a subset of six-items, with similar psychometric properties [48], which was determined using confirmatory factor analyses to have acceptable to excellent fit across most time points in our data $(20 \min \mathrm{CFI}=0.91, \mathrm{RMSEA}=0.07, \mathrm{SRMR}=0.06 ; 50 \mathrm{~min} \mathrm{CFI}=0.91$, $\mathrm{RMSEA}=0.12, \mathrm{SRMR}=0.04 ; 110 \mathrm{~min} \mathrm{RMSEA}=0.99, \mathrm{RMSEA}=$ 0.03 , SRMR $=0.04)$, unlike the original BAES $(\mathrm{CFI}<0.90$; RMSEA and SRMR $>0.08$ ).

Other outcomes

Impulsivity was determined at the baseline ADP using the abbreviated Barratt Impulsiveness Scale-11 [49]. This eight-item self-report yields two, four-items subscales: (lack of) SelfRegulation $(a=0.75)$ and Impulsive Behavior $(a=0.72)$.

Adverse events were determined daily during the treatment periods and at follow ups using the SAFTEE [50].

\section{DATA ANALYSES}

The original analytic plan included two primary outcomes of interest: total drinks consumed and craving (AUQ) during the adlib periods, each tested on an intent-to-treat (ITT) basis at the $a=$ 0.05 threshold. Descriptive statistics were performed prior to statistical analysis. Data were checked for normality and transformations applied as necessary. Post-baseline outcomes were compared to baseline levels. The total number of drinks consumed was analyzed using a linear mixed model that included TRT (NTX, NTX + MEM) as a within-subjects factor, sequence (SEQ) of TRT assignment as a between-subjects factor, and total drinks consumed during the baseline ADP as a covariate. Subjective craving (AUQ) was quantified by calculating an area under the curve (AUC) for each phase (priming dose, adlib) within each ADP, and AUCs were log-transformed to normality and analyzed using an identical linear mixed model as described for total drinks consumed. Potential confounding factors (sex, age, baseline drinking variables, smoking) were considered in each model, but they were not significant and were dropped for parsimony. Similar models were used to assess BAES outcomes. The effect of impulsivity was explored by including it in the analytical models for the drinking and craving outcomes. For all models, the bestfitting variance-covariance structure was based on the SchwartzBayesian Criterion (BIC). Least-square means were estimated and plotted to determine the nature of significant effects. All analyses were performed using SAS, version 9.4 (Cary, NC).

With 70 subjects planned, we had $80 \%$ power to detect less than a full drink reduction $(-0.8)$ in drinking due to the combination NTX + MEM compared to NTX alone (Cohen's $\mathrm{d}^{\prime}=$ 0.34 ) assuming alpha $=0.05$ and a two-sided test. Due to slower than anticipated recruitment, we recruited 56 subjects, and were powered to detect an effect size of $d^{\prime}=0.38$ or just under a full drink reduction $(-0.9)$.

\section{RESULTS}

Figure 1 illustrates the flow of participants through the study. Following initial eligibility determination, 64 subjects completed ADP1. Of these, eight were excluded because they did not consume any drinks in ADP1. Thus, the final sample was composed of 56 participants who were randomized to receive one of the two treatment sequences: (1) NTX + MEM followed by NTX $(n=26)$ or 2$)$ NTX followed by NTX + MEM $(n=30)$. The number of treatment days did not differ by treatment (NTX alone: $6.07, \mathrm{SD}=0.25 ; \mathrm{NTX}+\mathrm{MEM}: 6.11, \mathrm{SD}=0.3$ ), and 19 participants in the NTX + MEM-NTX group and 25 in the NTX-NTX + MEM group completed all study procedures.

\section{Baseline characteristics}

The final sample (see Table 1) included 33 men and 23 women, with an average age of 33.1 (SD $=8.9$ ), a diverse racial distribution (36 Caucasian, 19 African American, one other), an equal number of smokers and nonsmokers, and mean scores of 12.1 (SD = 5.6) on the Alcohol Dependence Scale [51]. During the 30 days prior to the baseline ADP, participants consumed, on average 165 (SD = 72) drinks, 7.2 drinks per drinking occasion $(S D=2.7)$ and drank 3 out of every 4 days $(76 \%, S D=16 \%)$. None of these participants were on antidepressants/anxiolytics.

Primary outcomes

Drinking. Descriptive statistics of each outcome are presented in Table 2 and in Fig. 2 (Panel A) which shows that both NTX (mean difference from baseline ADP: $-1.8 ; 95 \% \mathrm{Cl}:-2.7,-0.9)$ and NTX + MEM (mean difference from baseline ADP: $-2.7 ; 95 \%$ $\mathrm{Cl}:-3.4,-1.6)$ reduced drinking from the baseline ADP1. In the primary model, after adjusting for drinks consumed during ADP1, there was a significant TRT ${ }^{*}$ SEQ interaction $[\mathrm{F}(1,42)=9.2, p=$ 0.004)] suggesting that reductions due to the NTX + MEM combination were dependent on the sequence in which participants received treatment (Fig. 2, Panel B). Specifically, among participants who received NTX alone during the ADP2 followed by NTX + MEM in ADP3, a further significant reduction (mean: $-1.94 ; 95 \% \mathrm{Cl}:-2.6,-0.8$ ) in drinking was observed following the combined treatment $[\mathrm{F}(1,42)=14.1, p=0.0005)]$. In contrast, among the participants who received NTX + MEM in ADP2, the decline in drinking they experienced from baseline ADP was maintained and was not further reduced (mean: 0.59; $95 \%$ $\mathrm{Cl}:-0.67,1.43)$ with NTX alone treatment in $\operatorname{ADP3}[\mathrm{F}(1,42)=0.54$, $p=0.47)]$.

Craving. As shown in Table 2, and Fig. 3a, both treatments reduced craving from baseline during both PD and ad-lib phases of the ADP. Like results from the drinking model, treatment effects on craving during the ad-lib drinking phase appeared dependent on which drug combination was received first (TRT ${ }^{*}$ SEQ: $F(1,42)=3.0, p=.09$ ). Specifically, as seen in Fig. 3b, among participants who received NTX alone during ADP2 followed by NTX + MEM in ADP3, a further reduction in craving was observed following NTX + MEM compared to NTX alone (mean: -0.18 ; 95\% Cl: $-0.32,-0.05 ; \mathrm{F}(1,42)=7.5, p=0.009)$. In contrast, among participants who received NTX + MEM during ADP2, no further reduction in craving was observed following NTX alone during ADP3 (mean: $-0.01 ; 95 \% \mathrm{Cl}$ : -0.16 , $0.15 ; \mathrm{F}(1,42)=0.01, p=0.94)$.

\section{Secondary outcomes}

Brief Biphasic Alcohol Effects Scale. Reductions from baseline ADP in alcohol-induced stimulation were observed for both treatments (Table 2). However, no significant treatment differences were observed in the primary models which included baseline stimulation and sequence $[F(1,42)=0.03, p=0.87)]$. No treatment related differences were observed for alcohol-induced sedation.

Exploratory outcomes

Barratt Impulsiveness Scale -11. No significant changes in treatment effects were observed following inclusion of the BIS11 subscales in the primary models for the drinking and craving outcomes.

Adverse events. Overall, adverse events following treatment with NTX + MEM were similar to NTX only (Supplemental Table 1). The most common adverse events reported were typical for NTX [52], and use of MEM in heavy drinkers [19], and included nausea (NTX 
Influence of combined treatment with naltrexone and memantine on alcohol...

S Krishnan-Sarin et al.

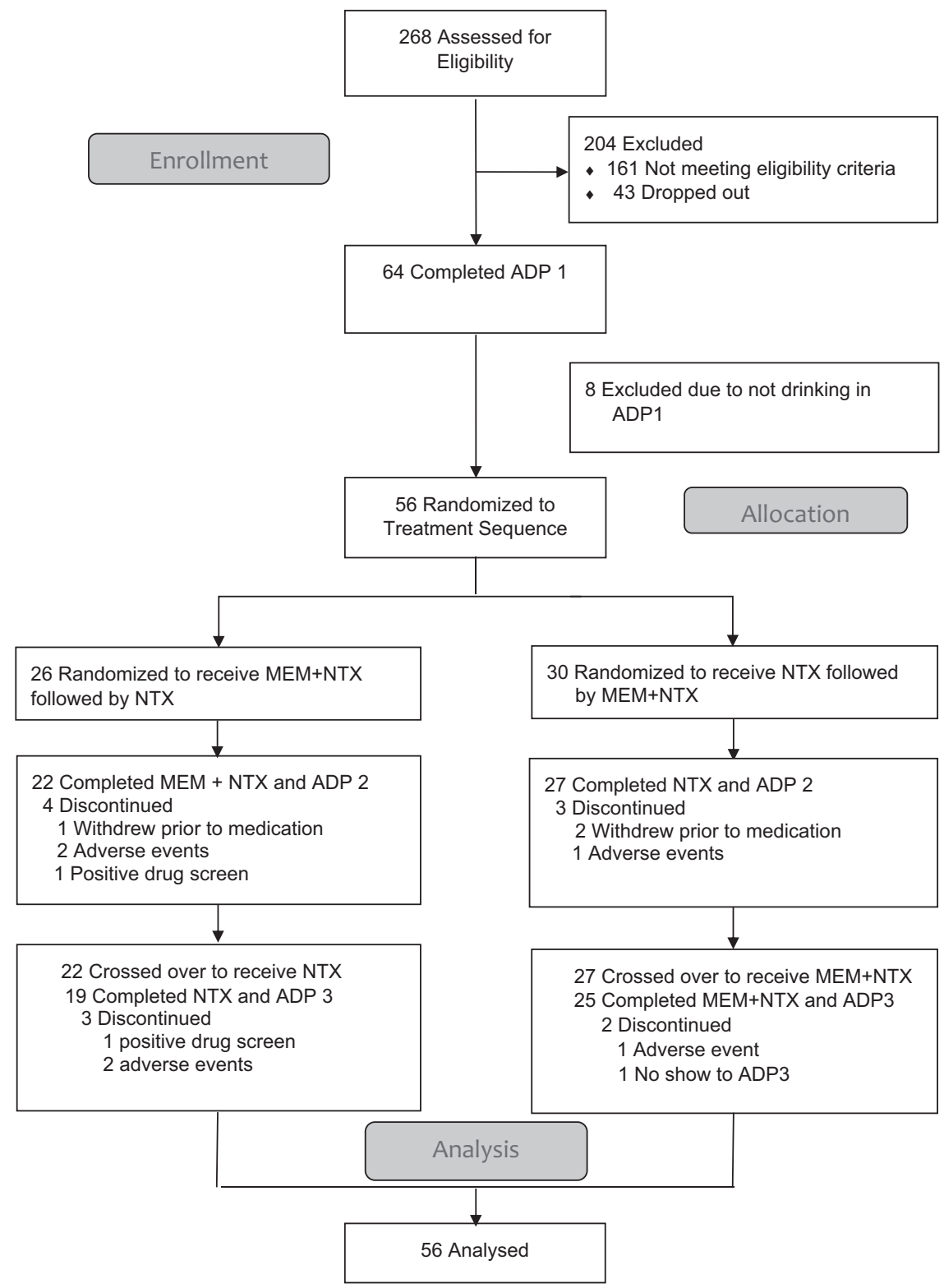

Fig. 1 Consort diagram

Table 1. Demographic table by treatment sequence

\begin{tabular}{|c|c|c|c|c|}
\hline & All subjects & NTX followed by NTX + MEM $(n=30)$ & NTX + MEM followed by NTX $(n=26)$ & $P$-value \\
\hline Male, $n(\%)$ & $33(59 \%)$ & $18(60 \%)$ & $15(58 \%)$ & 0.86 \\
\hline White, $n(\%)$ & $36(64 \%)$ & $20(67 \%)$ & $16(62 \%)$ & 0.69 \\
\hline Age (SD) & $33(8.9)$ & $32(9.3)$ & $34(8.5)$ & 0.57 \\
\hline Drinks/drinking day, mean (SD) & $7.2(2.7)$ & $7.2(2.9)$ & $7.2(2.5)$ & 0.99 \\
\hline$\%$ drinking days (SD) & $76(16)$ & $75(17)$ & $78(16)$ & 0.46 \\
\hline Alcohol Dependence Score & $12.1(5.6)$ & $11.3(5.7)$ & $13.1(5.5)$ & 0.24 \\
\hline
\end{tabular}


Table 2. Descriptive statistics of primary and secondary outcomes by treatment condition overall and by sequence of treatment assignment

\begin{tabular}{|c|c|c|c|c|c|c|c|c|c|}
\hline Outcome & \multicolumn{3}{|l|}{ Overall } & \multicolumn{3}{|c|}{ NTX followed by MEM + NTX } & \multicolumn{3}{|c|}{ MEM + NTX followed by NTX } \\
\hline Craving: priming & $7.03(0.56)$ & $6.84(0.57)^{* *}$ & $6.81(0.55)^{* *}$ & $7.02(0.60)$ & $6.87(0.60)^{*}$ & $6.79(0.60)^{* *}$ & $7.05(0.52)$ & $6.78(0.53)$ & $6.84(0.49)$ \\
\hline Craving: adlib & $7.95(0.56)$ & $7.75(0.55)^{* *}$ & $7.62(0.54)^{* * *}$ & $7.93(0.60)$ & $7.81(0.57)^{* *}$ & $7.57(0.58)^{* * *}$ & $7.97(0.52)$ & $7.67(0.54)^{* *}$ & $7.68(0.50)^{* *}$ \\
\hline Stimulation: adlib & $6.35(2.68)$ & $4.93(3.45)^{* *}$ & $4.78(3.51)^{* *}$ & $6.30(2.73)$ & $5.57(3.24)$ & $4.74(3.50)^{*}$ & $6.41(2.68)$ & $4.02(3.63)^{* * * *}$ & $4.83(3.60)^{*}$ \\
\hline Sedation: priming & $4.15(2.31)$ & $3.76(2.34)$ & $3.87(2.49)$ & $3.91(2.49)$ & $3.55(2.51)$ & $3.96(2.38)$ & $4.42(2.10)$ & $4.06(2.09)$ & $3.78(2.64)$ \\
\hline Sedation: adlib & $5.88(2.51)$ & $5.34(3.08)$ & $5.42(2.97)$ & $5.95(2.51)$ & $5.13(3.33)$ & $5.47(3.06)$ & $5.79(2.56)$ & $5.63(2.76)$ & $5.37(2.94)$ \\
\hline
\end{tabular}

Values represent mean (SD); asterisks indicate significantly different from baseline, ${ }^{*} p<0.05,{ }^{* *} p<0.01, * * * p 0.001$; AUQ Craving and BAES stimulation and sedation are log-transformed and represent the area under the curve (AUC) during the priming dose phase or adlib drinking phase as indicated

Panel A

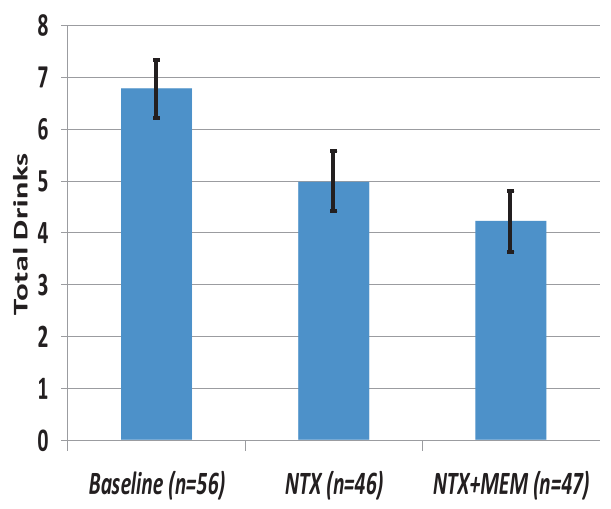

Panel B

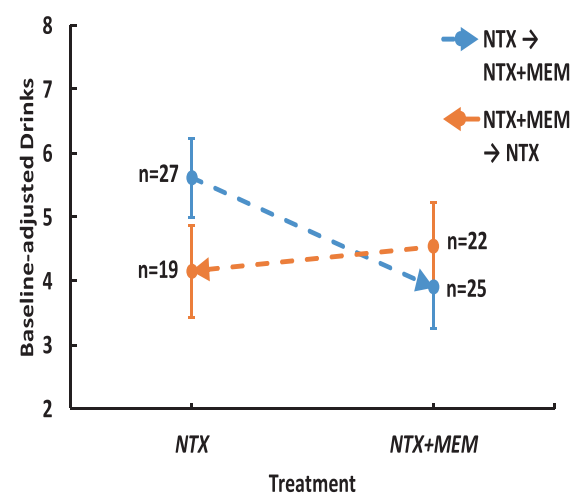

Fig. 2 Number of Drinks Consumed following Naltrexone (NTX) and Naltrexone + Memantine (NTX + MEM) (Panel A: Treatment, $p=0.06$; Panel B: Baseline-adjusted least-square means and standard errors; Treatment* sequence, $p=0.004$; the blue line represents the treatment sequence NTX followed by NTX + MEM and the orange line represents treatment sequence NTX = MEM followed by NTX

alone: 40\%; NTX + MEM: 42.3\%), headache (NTX alone: 22\%; NTX + MEM: $23.1 \%$ ), decreased appetite (NTX alone: $18 \%$; NTX + MEM: 19.2\%) and dizziness (NTX alone: 16\%; NTX + MEM: $21.2 \%$.). Of note, higher rates of "feeling high" were reported with NTX + MEM (13.5\%) compared with NTX alone (2\%). There were no serious adverse events.

\section{DISCUSSION}

In support of our hypothesis we observed that combined targeting of the opioid and glutamate systems with naltrexone and memantine produced greater reduction in alcohol drinking and alcohol craving, when compared with targeting the opioid system alone with naltrexone. However, in our crossover design, the reduction in drinking was dependent on the sequence in which the treatments were administered. Specifically, the number of drinks consumed was reduced from the baseline ADP when NTX was administered first and then further reduced by crossover treatment with NTX + MEM (mean: -1.94 drinks; Table 2). Since each drink was designed to raise BAC levels by $0.015 \mathrm{mg} / \mathrm{ml}$, this reduction would translate to $0.029 \mathrm{gm} / \mathrm{dl}$, which is the equivalent of 1-2 standard drinks. However, when NTX + MEM was given first, the number of drinks declined to levels similar to those observed following the combined treatment in the alternative sequence, but no further decline was observed following crossover treatment with NTX. In parallel, when examining the influence of the combined treatment on alcohol craving during the ad-lib period, a trend toward similar treatment* ${ }^{*}$ sequence effects as those seen for drinking were observed (Table 2). Thus, it appeared that memantine's beneficial effects on drinking persisted following discontinuation of memantine treatment. Of note, both treatments, i.e., NTX alone and NTX + MEM individually led to significant reductions in drinking and craving in the posttreatment ADP's compared to the baseline ADP, and in alcoholinduced stimulation but not sedation (Table 2).

It is not yet clear why memantine had persisting effects in this study. It is possible, that by altering craving or some aspect of the response to alcohol, memantine altered learning that occurred while drinking in the ADP. Alternatively, it is possible that low levels of memantine persisted in the blood or brain through the second treatment period, obscuring the difference between the memantine and placebo conditions. Memantine has fairly linear pharmacokinetics with $80 \%$ of the circulating dose in the form of the parent molecule, and a long termination half-life of $60-80 \mathrm{~h}$ [53-56], Therefore, it could be estimated that following a 6-day washout only a quarter of the $20 \mathrm{mg}$ dose was actually eliminated, 
Panel A

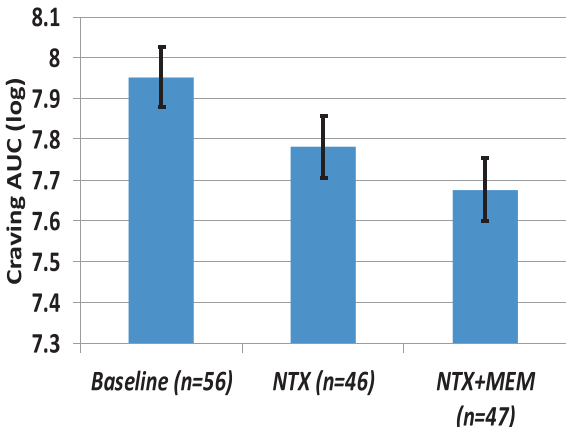

Panel B

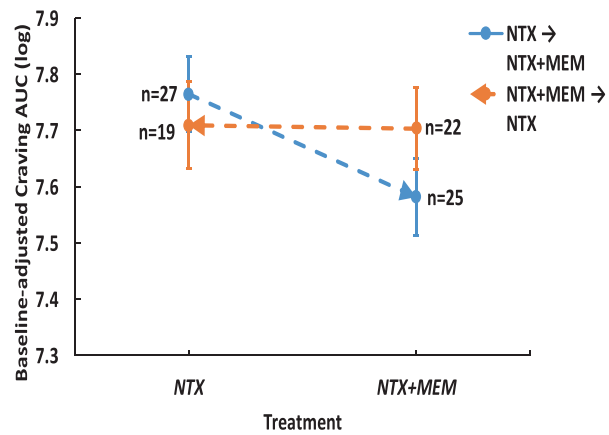

Fig. 3 Alcohol Craving (AUQ) following treatment with Naltrexone (NTX) and Naltrexone + Memantine (NTX + MEM) during the ad-lib drinking phase (Panel A: Treatment effect, $p<0.05$; Panel B: Baseline-adjusted least-square means and standard errors; Treatment* sequence, $p=0.09$; the blue line represents the treatment sequence NTX followed by NTX + MEM and the orange line represents treatment sequence NTX + MEM followed by NTX

suggesting that among those who received the NTX + MEM first, there may still be a sufficient amount of memantine remaining to maintain the beneficial effects on drinking when combined with naltrexone in the crossover condition. While this hypothesis would need to be confirmed, existing preclinical evidence does suggest that low doses of memantine can produce NMDAR related effects [57-59], and that a low (5 mg/day) dose of memantine, when combined with other treatments, may reduce alcohol drinking [17].

The sustained effects of memantine could also be related to the fact that we studied FHP drinkers. Family history of alcoholism has been shown to be a predictor of a robust and sustained antidepressant response to the NMDAR antagonist ketamine [60-62]. In fact, one study demonstrated that the antidepressant efficacy of ketamine may persist up to 4 weeks longer for those who have a positive family history of alcoholism [61], and that this effect is independent of the presence of an AUD. While the reason for this extended efficacy is not known, it may be related to sustained neurobiological changes produced by the NMDA antagonist. Further, alcohol, which was administered in the current study, is known to be a weak NMDA antagonist [63-65], and could in combination with memantine also prolong NMDA-R blockade.

Regarding adverse events, the combination of NTX + MEM had a relatively similar profile to that of NTX alone, with nausea and headache most commonly reported. Further, there were no increases in alcohol-induced stimulation or sedation following either treatment condition, and we also did not observe any interactive effects of impulsivity on drinking. Therefore, it appears the combination of $20 \mathrm{mg} /$ day of MEM and $50 \mathrm{mg} /$ day of NTX was well tolerated, and in contrast to prior findings with use of a higher memantine dose alone [19], the combination did not lead to increased drinking or craving among more impulsive drinkers.

Interestingly, earlier studies examining the effects of combined treatment with memantine and opioid agents in the treatment of opioid use disorders, have shown modest benefits in combination with morphine [66] or with buprenorphine/naloxone [67], and no benefit in combination with naltrexone $[68,69]$. These discrepant findings could be related to the high doses of memantine used in some of these studies which, as we have suggested, may result in uncompetitive blockade of NMDA-R signaling, compromise executive control and impulsive responding, and be counterproductive for targeting addictive behaviors [19]. Further, the interactions between the mu-opioid and NMDA systems are complex and dose dependent. For example, a low dose of naltrexone when combined with a low dose of ketamine increased symptoms of anxiety and anhedonia, but similar effects were not observed when a low dose naltrexone was combined with a high dose of ketamine [30]. Further, low doses of memantine have been shown to reduce morphine-induced place preference in rats (Chen et al. [70]) and memantine when combined with a weak mu-receptor agonist (buprenorphine) and a low dose of naloxone appears to be beneficial for opioid use disorder treatment [67]. Our evidence suggests that the combined use of a low dose of memantine and a moderate dose of naltrexone reduces alcohol drinking and craving in individuals with AUD. Future studies should examine if low doses of memantine have beneficial effects on the treatment of other addictive behaviors that involve the opioid system and/or respond to opiate antagonists.

Future research should also address the limitations of the current proof-of-concept study that was conducted in FHP heavy drinkers and used a well-controlled alcohol drinking paradigm. To evaluate the generalizability of our findings, a larger randomized controlled trial that includes family history positive and negative drinkers and those with variable severity of AUD is needed. We also tested a limited range of doses; the efficacy of combinations of lower doses of both agents, which would have fewer adverse events, should be evaluated. Due to the lack of a full-factorial design, we were also unable to address the optimal sequencing of naltrexone and memantine, but we speculate that perhaps treatment should be initiated with naltrexone, a first line and faster acting treatment, and then followed by memantine that takes longer to reach steady state levels. Future studies also need to assess memantine pharmacokinetics as a predictor of variability in responses and should be powered to examine the predictive utility of subjective symptoms like "feeling high", as well as medication-induced changes in alcohol-induced stimulation, in treatment response. Finally, for ethical reasons we conducted this study with non-treatment-seeking drinkers; evidence of differences in treatment response between treatment-seeking and nontreatment-seeking drinkers [71, 72] suggests that it will be important to examine the effects of the combined treatment among drinkers who are trying to stop or reduce their drinking behaviors.

In summary, our evidence suggests that combined targeting of both NMDA and opioid receptors may hold promise for the treatment of alcohol drinking. Future clinical trials should consider using low doses of NMDA antagonists to enhance the efficacy of the opioid antagonist naltrexone in reducing drinking behaviors.

\section{FUNDING AND DISCLOSURE}

This research was supported by grant P50 AA021818 from the National Institute on Alcohol Abuse and Alcoholism and CTSA 
Grant Number UL1 TR001863 from the National Center for Advancing Translational Science (NCATS), both components of the National Institutes of Health (NIH). The content is solely the responsibility of the authors and does not necessarily represent the official views of the $\mathrm{NIH}$. While unrelated to the current study, Dr. Krishnan-Sarin received donated study medications from Novartis, Astra-Zeneca and Pfizer. Dr. O'Malley reports receiving being a NIDA Clinical Trials Network DSMB member with honorarium from the Emmes Corporation, compensation as a member of the American Society of Clinical Psychopharmacology workgroup (ACTIVE), which has been supported in the past 36 months by Alkermes, Amygdala Neurosciences, Arbor Pharmaceuticals, Indivior, Lundbeck, Mitsubishi Tanabe, and Otsuka; consultation to Mitsubishi Tanabe, Indivior, Opiant, and Alkermes with compensation, and study medications from Astra Zeneca, Novartis and Pfizer. Dr. Krystal reports compensation $(\$ 10,000)$ as the Editor of Biological Psychiatry. He also serves on the Scientific Advisory Boards for Bioasis Technologies, Inc., Biohaven Pharmaceuticals, BioXcel Therapeutics, Inc. (Clinical Advisory Board), Cadent Therapeutics (Clinical Advisory Board), PsychoGenics, Inc, Stanley Center for Psychiatric research at the Broad Institute of MIT and Harvard and the Lohocla Research Corporation. He owns stock in ArRETT Neuroscience, Inc., Biohaven Pharmaceuticals, Sage Pharmaceuticals, and Spring Care, Inc. and stock options in Biohaven Pharmaceuticals Medical Sciences, BlackThorn Therapeutics, Inc. and Storm Biosciences, Inc. He is a co-inventor on multiple patents as listed below: (1) Seibyl JP, Krystal JH, Charney DS. Dopamine and noradrenergic reuptake inhibitors in treatment of schizophrenia. US Patent \#:5,447,948.September 5, 1995, (2) Vladimir, Coric, Krystal, John H, Sanacora, Gerard-Glutamate Modulating Agents in the Treatment of Mental Disorders US Patent No. 8,778,979 B2 Patent Issue Date: July 15, 2014. US Patent Application No. 15/695,164: Filing Date: 09/05/2017, (3) Charney D, Krystal JH, Manji H, Matthew S, Zarate C.-Intranasal Administration of Ketamine to Treat Depression United States Application No. 14/197,767 filed on March 5, 2014; United States application or Patent Cooperation Treaty (PCT) International application No. 14/ 306,382 filed on June 17, 2014, (4): Zarate, C, Charney, DS, Manji, HK, Mathew, Sanjay J, Krystal, JH, Department of Veterans Affairs "Methods for Treating Suicidal Ideation", Patent Application No. 14/197.767 filed on March 5, 2014 by Yale University Office of Cooperative Research, (5) Arias A, Petrakis I, Krystal JH.Composition and methods to treat addiction. Provisional Use Patent Application no.61/973/961. April 2, 2014. Filed by Yale University Office of Cooperative Research, (6) Chekroud, A., Gueorguieva, R., \& Krystal, JH. "Treatment Selection for Major Depressive Disorder" [filing date 3rd June 2016, USPTO docket number Y0087.70116US00]. Provisional patent submission by Yale University, (7) Gihyun, Yoon, Petrakis I, Krystal JH-Compounds, Compositions and Methods for Treating or Preventing Depression and Other Diseases. U. S. Provisional Patent Application No. 62/444,552, filed on January 10, 2017 by Yale University Office of Cooperative Research OCR 7088 US01, (8) Abdallah, C, Krystal, JH, Duman, R, Sanacora, G. Combination Therapy for Treating or Preventing Depression or Other Mood Diseases. U.S. Provisional Patent Application No. 047162-7177P1 (00754) filed on August 20, 2018 by Yale University Office of Cooperative Research OCR 7451 US01. None of the other authors have any disclosures.

\section{ADDITIONAL INFORMATION}

Supplementary Information accompanies this paper at (https://doi.org/10.1038/ s41386-019-0536-z).

Publisher's note Springer Nature remains neutral with regard to jurisdictional claims in published maps and institutional affiliations.

\section{REFERENCES}

1. Grant KA, Lovinger DM. Cellular and behavioral neurobiology of alcohol: receptor-mediated neuronal processes. Clin Neurosci. 1995;3:155-64.

2. Gass JT, Olive MF. Glutamatergic substrates of drug addiction and alcoholism. Biochem Pharm. 2008;75:218-65.

3. Woodward JJ. lonotropic glutamate receptors as sites of action for ethanol in the brain. Neurochem Int. 1999;35:107-13.

4. Krystal JH, Petrakis IL, Mason G, Trevisan L, D'Souza DC. N-methyl-D-aspartate glutamate receptors and alcoholism: reward, dependence, treatment, and vulnerability. Pharm Ther. 2003a;99:79-94.

5. Petrakis IL, Limoncelli D, Gueorguieva R, Jatlow P, Boutros NN, Trevisan L, et al. Altered NMDA glutamate receptor antagonist response in individuals with a family vulnerability to alcoholism. Am J Psychiatry. 2004;161:1776-82.

6. Yoon G, Pittman B, Limoncelli D, Krystal JH, Petrakis IL. Familial alcoholism risk and the ratio of stimulant to sedative effects of ketamine. Biol Psychiatry. 2016;79:e69-70.

7. Krystal JH, Petrakis IL, Trevisan L, D'Souza DC. NMDA receptor antagonism and the ethanol intoxication signal: From alcoholism risk to pharmacotherapy. Ann $\mathrm{N}$ Y Acad Sci. 2003b;1003:176-84.

8. Acosta G, Hasenkamp W, Daunais JB, Friedman DP, Grant KA, Hemby SE. Ethanol self-administration modulation of NMDA receptor subunit and related synaptic protein mRNA expression in prefrontal cortical fields in cynomolgus monkeys. Brain Res. 2010;1318:144-54.

9. Clapp P, Gibson ES, Dell'acqua ML, Hoffman PL. Phosphorylation regulates removal of synaptic N-methyl-D-aspartate receptors after withdrawal from chronic ethanol exposure. J Pharm Exp Ther. 2010;332:720-9.

10. Roberto M, Varodayan FP. Synaptic targets: chronic alcohol actions. Neuropharmacology. 2017;122:85-99.

11. Prisciandaro JJ, Schacht JP, Prescot AP, Brenner HM, Renshaw PF, Brown TR, et al. Intraindividual changes in brain GABA, glutamate, and glutamine during monitored abstinence from alcohol in treatment-naive individuals with alcohol use disorder. Addict Biol. 2019;1:e12810.

12. Escher T, Call SB, Blaha CD, Mittleman G. Behavioral effects of aminoadamantane class NMDA receptor antagonists on schedule-induced alcohol and selfadministration of water in mice. Psychopharmacol (Berl). 2006;187:424-34.

13. Krupitsky EM, Neznanova O, Masalov D, Burakov AM, Didenko T, Romanova T, et al. Effect of memantine on cue-induced alcohol craving in recovering alcoholdependent patients. Am J Psychiatry. 2007a;164:519-23.

14. Krupitsky EM, Rudenko AA, Burakov AM, Slavina TY, Grinenko AA, Pittman B, et al. Antiglutamatergic strategies for ethanol detoxification: comparison with placebo and diazepam. Alcohol Clin Exp Res. 2007b;31:604-11.

15. Arias AJ, Feinn R, Covault J, Kranzler HR. Memantine for alcohol dependence: an open-label pilot study. Addictive Disord Their Treat. 2007;6:77-83.

16. Bisaga A, Evans SM. Acute effects of memantine in combination with alcohol in moderate drinkers. Psychopharmacol (Berl). 2004;172:16-24.

17. Lee SY, Wang TY, Chen SL, Chang YH, Chen PS, Huang SY, et al. Add-on memantine treatment for bipolar II disorder comorbid with alcohol dependence: a 12week follow-up study. Alcohol Clin Exp Res. 2018;42:1044-50.

18. Jamadar S, DeVito EE, Jiantonio RE, Meda SA, Stevens MC, Potenza MN, et al. Memantine, an NMDA receptor antagonist, differentially influences Go/No-Go performance and fMRI activity in individuals with and without a family history of alcoholism. Psychopharmacol (Berl). 2012;222:129-40.

19. Krishnan-Sarin S, O'Malley SS, Franco N, Cavallo DA, Morean M, Shi J, et al. Nmethyl-D-aspartate receptor antagonism has differential effects on alcohol craving and drinking in heavy drinkers. Alcohol Clin Exp Res. 2015; 39:300-7.

20. Alasmari F, Goodwani S, McCullumsmith RE, Sari Y. Role of glutamatergic system and mesocorticolimbic circuits in alcohol dependence. Prog Neurobiol. 2018;171:32-49.

21. Koob GF, Volkow ND. Neurobiology of addiction: a neurocircuitry analysis. Lancet Psychiatry. 2016;3:760-73.

22. Chartoff EH, Connery HS. It's MORe exciting than mu: crosstalk between mu opioid receptors and glutamatergic transmission in the mesolimbic dopamine system. Front Pharm. 2014;5:116.

23. Gracy KN, Svingos AL, Pickel VM. Dual ultrastructural localization of mu-opioid receptors and NMDA-type glutamate receptors in the shell of the rat nucleus accumbens. J Neurosci. 1997;17:4839-48.

24. Huang J, Wang $\mathrm{H}$, Pickel VM. Rostrocaudal variation in targeting of $\mathrm{N}$-methyl-Daspartate and mu-opioid receptors in the rat medial nucleus of the solitary tract. J Comp Neurol. 2000;421:400-11.

25. Danysz W, Kozela E, Parsons CG, Sladek M, Bauer T, Popik P. Peripherally acting NMDA receptor/glycineB site receptor antagonists inhibit morphine tolerance. Neuropharmacology. 2005;48:360-71.

26. Harris AC, Rothwell PE, Gewirtz JC. Effects of the NMDA receptor antagonist memantine on the expression and development of acute opiate dependence as 
assessed by withdrawal-potentiated startle and hyperalgesia. Psychopharmacol (Berl). 2008;196:649-60.

27. Popik P, Kozela E, Danysz W. Clinically available NMDA receptor antagonists memantine and dextromethorphan reverse existing tolerance to the antinociceptive effects of morphine in mice. Naunyn Schmiedebergs Arch Pharm. 2000:361:425-32.

28. Trujillo KA, Akil H. Inhibition of morphine tolerance and dependence by the NMDA receptor antagonist MK-801. Science. 1991;251:85-87.

29. Trujillo KA, Akil H. Inhibition of opiate tolerance by non-competitive N-methyl-Daspartate receptor antagonists. Brain Res. 1994;633:178-88.

30. Krystal JH, Madonick S, Perry E, Gueorguieva R, Brush L, Wray Y, et al. Potentiation of low dose ketamine effects by naltrexone: potential implications for the pharmacotherapy of alcoholism. Neuropsychopharmacology. 2006;31:1793-800.

31. Nie Z, Yuan X, Madamba SG, Siggins GR. Ethanol decreases glutamatergic synaptic transmission in rat nucleus accumbens in vitro: naloxone reversal. J Pharm Exp Ther. 1993;266:1705-12.

32. Krishnan-Sarin S, Krystal JH, Shi J, Pittman B, O'Malley SS. Family history of alcoholism influences naltrexone-induced reduction in alcohol drinking. Biol Psychiatry. 2007;62:694-7.

33. Reus VI, Fochtmann LJ, Bukstein O, Eyler AE, Hilty DM, Horvitz-Lennon M, et al. The American Psychiatric Association Practice Guideline for the pharmacological treatment of patients with alcohol use disorder. Am J Psychiatry. 2018;175:86-90

34. George DT, Herion DW, Jones CL, Phillips MJ, Hersh J, Hill D, et al. Rimonabant (SR141716) has no effect on alcohol self-administration or endocrine measures in nontreatment-seeking heavy alcohol drinkers. Psychopharmacol (Berl). 2010;208:37-44.

35. Anton RF, Drobes DJ, Voronin K, Durazo-Avizu R, Moak D. Naltrexone effects on alcohol consumption in a clinical laboratory paradigm: temporal effects of drinking. Psychopharmacol (Berl). 2004;173:32-40.

36. McKee SA, Harrison EL, O'Malley SS, Krishnan-Sarin S, Shi J, Tetrault JM, et al. Varenicline reduces alcohol self-administration in heavy-drinking smokers. Biol Psychiatry. 2009;66:185-90.

37. McKee SA, O'Malley SS, Shi J, Mase T, Krishnan-Sarin S. Effect of transdermal nicotine replacement on alcohol responses and alcohol self-administration. Psychopharmacol (Berl). 2008;196:189-200.

38. O'Malley SS, Krishnan-Sarin S, Farren C, Sinha R, Kreek MJ. Naltrexone decreases craving and alcohol self-administration in alcohol-dependent subjects and activates the hypothalamo-pituitary-adrenocortical axis. Psychopharmacol (Berl). 2002;160:19-29.

39. Voronin K, Randall $P$, Myrick $H$, Anton R. Aripiprazole effects on alcohol consumption and subjective reports in a clinical laboratory paradigm-possible influence of self-control. Alcohol Clin Exp Res. 2008;32:1954-61.

40. NACAA. Recommended council guidelines on ethyl alcohol adminstration in human experimentation. 2006. https://www.niaaa.nih.gov/Resources/ResearchResources/ job22.htm.

41. Sobell L, Sobell M. Timeline Follow-back: A technique for assessing self-reported alcohol consumption. In: Litten R, Allen J, (eds). Measuring alcohol consumption: psychological and biological methods. New Jersey: Humana Press; 1992. p. 41-72.

42. Rice JP, Reich T, Bucholz KK, Neuman RJ, Fishman R, Rochberg N, et al. Comparison of direct interview and family history diagnoses of alcohol dependence. Alcohol Clin Exp Res. 1995;19:1018-23.

43. First MB, Spitzer RL, Gibbon M, Williams, JB. Structured llinical interview for the DSM-IV Axis I disorders. 1996.

44. Sullivan JT, Sykora K, Schneiderman J, Naranjo CA, Sellers EM. Assessment of alcohol withdrawal: the revised clinical institute withdrawal assessment for alcohol scale (CIWA-Ar). Br J Addict. 1989;84:1353-7.

45. Watson PE (1989). Total body water and alcohol levels:updating the fundamentals. In: Krow KE, Batt RD (eds). Human metabolism of alcohol. CRC press, pp. 41-66.

46. Bohn MJ, Krahn DD, Staehler BA. Development and initial validation of a measure of drinking urges in abstinent alcoholics. Alcohol Clin Exp Res. 1995;19:600-6.

47. Martin CS, Earleywine M, Musty RE, Perrine MW, Swift RM. Development and validation of the Biphasic Alcohol Effects Scale. Alcohol Clin Exp Res. 1993;17:140-6.

48. Rueger SY, King AC. Validation of the brief Biphasic Alcohol Effects Scale (B-BAES). Alcohol Clin Exp Res. 2013;37:470-6.

49. Morean ME, DeMartini KS, Leeman RF, Pearlson GD, Anticevic A, Krishnan-Sarin S, et al. Psychometrically improved, abbreviated versions of three classic measures of impulsivity and self-control. Psychol Assess. 2014;26:1003-20.
50. Levine J, Schooler NR. SAFTEE: a technique for the systematic assessment of side effects in clinical trials. Psychopharmacol Bull. 1986;22:343-81.

51. Ross HE, Gavin DR, Skinner HA. Diagnostic validity of the MAST and the alcohol dependence scale in the assessment of DSM-III alcohol disorders. J Stud Alcohol. 1990;51:506-13.

52. Croop RS, Faulkner EB, Labriola DF. The safety profile of naltrexone in the treatment of alcoholism. Results from a multicenter usage study. The Naltrexone Usage Study Group. Arch Gen Psychiatry. 1997;54:1130-5.

53. Gomolin IH, Smith C, Jeitner TM. Once-daily memantine: pharmacokinetic and clinical considerations. J Am Geriatr Soc. 2010;58:1812-3.

54. Liu MY, Meng SN, Wu HZ, Wang S, Wei MJ. Pharmacokinetics of single-dose and multiple-dose memantine in healthy chinese volunteers using an analytic method of liquid chromatography-tandem mass spectrometry. Clin Ther. 2008;30:641-53.

55. Noetzli M, Eap CB. Pharmacodynamic, pharmacokinetic and pharmacogenetic aspects of drugs used in the treatment of Alzheimer's disease. Clin Pharmacokinet. 2013;52:225-41.

56. Periclou A, Ventura D, Rao N, Abramowitz W. Pharmacokinetic study of memantine in healthy and renally impaired subjects. Clin Pharm Ther. 2006;79:134-43.

57. Danysz W, Parsons CG, Kornhuber J, Schmidt WJ, Quack G. Aminoadamantanes as NMDA receptor antagonists and antiparkinsonian agents-preclinical studies. Neurosci Biobehav Rev. 1997;21:455-68.

58. Schmidt WJ, Zadow B, Kretschmer BD, Hauber W. Anticataleptic potencies of glutamate-antagonists. Amino Acids. 1991;1:225-37.

59. Wenk GL, Danysz W, Mobley SL. MK-801, memantine and amantadine show neuroprotective activity in the nucleus basalis magnocellularis. Eur J Pharm. 1995;293:267-70.

60. Luckenbaugh DA, Ibrahim L, Brutsche N, Franco-Chaves J, Mathews D, Marquardt $C A$, et al. Family history of alcohol dependence and antidepressant response to an N-methyl-D-aspartate antagonist in bipolar depression. Bipolar Disord. 2012;14:880-7.

61. Niciu MJ, Luckenbaugh DA, lonescu DF, Richards EM, Vande Voort JL, Ballard ED, et al. Ketamine's antidepressant efficacy is extended for at least four weeks in subjects with a family history of an alcohol use disorder. Int J Neuropsychopharmacol. 2014;18:pii: pyu039.

62. Phelps LE, Brutsche N, Moral JR, Luckenbaugh DA, Manji HK, Zarate CA Jr. Family history of alcohol dependence and initial antidepressant response to an Nmethyl-D-aspartate antagonist. Biol Psychiatry. 2009;65:181-4.

63. Fink K, Gothert M. Both ethanol and ifenprodil inhibit NMDA-evoked release of various neurotransmitters at different, yet proportional potency: potential relation to NMDA receptor subunit composition. Naunyn Schmiedebergs Arch Pharm. 1996:354:312-9.

64. Kash TL, Matthews RT, Winder DG. Alcohol inhibits NR2B-containing NMDA receptors in the ventral bed nucleus of the stria terminalis. Neuropsychopharmacology. 2008;33:1379-90.

65. Lovinger DM. Developmental decrease in ethanol inhibition of N-methyl-Daspartate receptors in rat neocortical neurons: relation to the actions of ifenprodil. J Pharm Exp Ther. 1995;274:164-72.

66. Bisaga A, Comer SD, Ward AS, Popik P, Kleber HD, Fischman MW. The NMDA antagonist memantine attenuates the expression of opioid physical dependence in humans. Psychopharmacol (Berl). 2001;157:1-10.

67. Gonzalez G, DiGirolamo G, Romero-Gonzalez M, Smelson D, Ziedonis D, Kolodziej M. Memantine improves buprenorphine/naloxone treatment for opioid dependent young adults. Drug Alcohol Depend. 2015;156:243-53.

68. Bisaga A, Sullivan MA, Cheng WY, Carpenter KM, Mariani JJ, Levin FR, et al. A placebo controlled trial of memantine as an adjunct to oral naltrexone for opioid dependence. Drug Alcohol Depend. 2011;119:e23-29.

69. Bisaga A, Sullivan MA, Glass A, Mishlen K, Carpenter KM, Mariani JJ, et al. A placebo-controlled trial of memantine as an adjunct to injectable extendedrelease naltrexone for opioid dependence. J Subst Abus Treat. 2014;46:546-52.

70. Chen SL, Tao PL, Chu CH, Chen SH, Wu HE, Tseng LF, Hong JS, Lu RB. Low-dose memantine attenuated morphine addictive behavior through its anti-inflammation and neurotrophic effects in rats. J Neuroimmune Pharmacol. 2012;7:444-53..

71. Ray LA, Bujarski S, Yardley MM, Roche DJO, Hartwell EE. Differences between treatment-seeking and non-treatment-seeking participants in medication studies for alcoholism: do they matter? Am J Drug Alcohol Abus. 2017:43:703-10.

72. Rohn MC, Lee MR, Kleuter SB, Schwandt ML, Falk DE, Leggio L. Differences between treatment-seeking and nontreatment-seeking alcohol-dependent research participants: an exploratory analysis. Alcohol Clin Exp Res. 2017:41:414-20. 